\title{
FUNGSI AFEKTIF DAN PERAWATAN KELUARGA DENGAN KEPATUHANPENGOBATAN TB PARU
}

\author{
Diandry Tamamengka \\ Billy Kepel \\ Sefti Rompas \\ Program Studi Ilmu Keperawatan Fakultas Kedokteran \\ Univeristas Sam Ratulangi \\ Email :diandry.tamamengka22@gmail.com
}

\begin{abstract}
Abstrack: The functions of Affective and Family Care, namely mutual respect and mutual support, foster care, in a way this is a family member feel got the attention, love, honor, the warmth. This important function is there to maintain the State of health of the family members to have a high productivity. The purpose of this research is to know the functions of affective Relationships and family care with Pulmonary TB treatment compliance in Clinics Tuminting Manado. Research methods design uses cross sectional techniques the taking of sampling using the technique of accidental sampling with the total sample as much as 68 respondents. Method of data collection using the questionnaire function of affective and family care with Pulmonary Tb treatment compliance and test statistic using the test chi square.Research results on p-values can be value of 0.001 and $0.003(\alpha \leq 0.05)$ which means there is a significant Relationship conclusion the results of this research show that there is a corelation of care and Affective function of families with Compliance with the treatment of Pulmonary tuberculosis in health center Tuminting Manado.
\end{abstract}

Keywords: Family Affective function, The function of Family care, Adherence to treatment.

Abstrak : Fungsi Afektif dan Perawatan Keluarga yaitu saling mendukung, menghormati dan saling asuh, dengan cara inilah seorang anggota keluarga merasa mendapat perhatian, kasih sayang, kehormatan, kehangatan. Fungsi ini penting ada untuk mempertahankan keadaan kesehatan anggota keluarga agar tetap memiliki produktivitas tinggi.Tujuan penelitian ini untuk mengetahui Hubungan fungsi afektif dan perawatan keluarga dengan kepatuhan pengobatan TB Paru di Puskesmas Tuminting Manado.Metode penelitian ini menggunakan desain cross sectional teknik pengambilan sampling menggunakan teknik accidental sampling dengan jumlah sampel sebanyak 68 responden.Metode pengumpulan data menggunakan kuesioner fungsi afektif dan perawatan keluarga dengan kepatuhan pengobatan Tb Paru dan Uji statistic menggunakan uji chi square.Hasil penelitian di dapat nilai p-value sebesar 0,001 dan $0,003(\leq \alpha 0,05)$ yang berarti ada Hubungan yang signifikan kesimpulan hasil penelitian ini menunjukan bahwa ada Hubungan Fungsi Afektif dan Perawatan Keluarga dengan Kepatuhan Pengobatan TB Paru di Puskesmas Tuminting Manado.

Kata kunci : Fungsi Afektif Keluarga, Fungsi perawatan keluarga, Kepatuhan pengobatan

\section{PENDAHULUAN}

Tuberkulosis merupakan penyakit menular langsung yang disebabkan oleh kuman tuberculosis. Infeksi ber-sifat sistemik sehingga dapat mengenai semua organ paru sebagai lokal infeksi primer. Tuberculosis (TB) merupakan masalah kesehatan masyarakat yang penting didunia. World Health Orga-nization (WHO) telah terdapat 182 kasus per 
100.000 penduduk di Afrika hampir 2 kali lebih besar asia tenggara yaitu 350 per 100.000 penduduk. (WHO 2009), Mengatakan Sebagaimana juga halnya di negara negara berkembang lain, TB di indonesia masih merupakan salah satu masalah kesehatan yang utama. Tuberkulosis merupakan penyakit sistemik yang dapat mengenai hampir semua organ tubuh, yaitu organ pernafasan. Kuman TB dapat hidup lama tanpa aktifitas dalam jaringan tubuh (dormant) hingga sampai saatnya ia aktif kembali. Lesi TB dapat sembuh tetapi dapat juga berkembang progresif atau mengalami proses kronik atau serius. Depkes RI , (2009)

Tuberkulosis paru (TB paru) merupakan salah satu penyakit yang telah lama dikenal dan sampai saat ini masih merupakan masalah kesehatan di berbagai Negara di dunia.Salah satu Negara berkembang yang terinfeksi kasus TB adalah Indonesia. Indonesia menempati peringkat ketiga jumlah penderita TB di dunia setelah india (1.762.000) dan china (1.459.000).

Depkes RI memperkirakan bahwa setiap tahun terdapat 528.000 kasus baru TB di Indonesia.Berdasarkan laporan hasil survey yang di lakukan oleh WHO dari tahun 2008 sampai dengan 2012 negara negara di dunia, bahwa penggunaan Directly observed Treatment Short Course (DOTS) dan strategi stop TB mampu menurunkan beban TB setiap tahunnya. Penggunaan DOTS dan strategi stop TB merupakan pengobatan dengan pengawasan langsung terapi dengan cara membantu pasien mengambil obat secara teratur untuk memastikan kepatuhan pasien dalam pengobatan TB paru. Kepatuhan pasien dalam pengobatan TB paru sangat berarti bahwa dunia berada di trek untuk mencapai tujuan Millenium Deve-lopment Goals (MDGs ) untuk mem-balikan penyebaran TB pada tahun 2015 dan angka kematian yang di sebabkan oleh TB paru menurun $45 \%$ dan diperkirakan sekitar 22 juta jiwa di dunia diselamatkan oleh program tersebut (WHO, 2013).

Pengobatan Tuberkulosis me merlukan waktu yang relatif panjang, dengan dua tahap, yaitu tahap awal (intensif) dan tahap lanjutan Depkes, (2010). Pada semua tahap tersebut pasien harus meminum obat dalam jangka waktu tertentu.Banyaknya obat yang harus diminum dan toksisitas sertaefek samping obat dapat menjadi peng-hambat dalam penyelesaian terapipasien Tuberkulosis WHO (2009). Kepatuhan rata-rata pasien pada pengobatan jangka panjang terhadap penyakitkronis di negara maju hanya sebesar $50 \%$ sedangkan di negara berkembang jumlah tersebut bahkan lebih rendah. Ketidak patuhan pasien dalam pengobatan merupakan masalah kese-hatan yang serius dan sering terjadi padapasien dengan penyakit kronis, seperti pada penyakit tuberkulosis paru.Banyak faktor yang berhubungan dengan kepatuhan terhadap terapi TB paru, termasuk karakteristik pasien, hubungan antara petugas pelayanan kesehatandan pasien, regimen terapi dan sistem penyelenggara pelayanan kesehatan DepkesRI, (2009).

Rukmini, (2011), dalam penelitiannya ia menemukan bahwa dukungan keluarga merupakan faktor penting keberhasilan pasien TB dalam mematuhi program pengobatan.Keluarga merupakan unit terkecil dari masyarakat yang besar pengaruhnya dalam kehidupan se-seorang. Terlebih lagi dalam kesehatan, keluarga dapat berperan aktif dalam melindungi anggota keluarganya yang sakit. Kemampuan keluarga dalam mem-berikan perawatan kesehatan mem-pengaruhi status kesehatan keluarga. Selain itu pengetahuan keluarga tentang sehat dan sakit juga mempengaruhi prilaku keluarga dalam menyelesaikan masalah kesehatan keluarga. Friedman membagi fungsi keluarga menjadi lima yaitu, Fungsi Afektif, Fungsi perawatan keluarga, Fungsi sosial, Fungsi rep-roduksi, Fungsi ekonomi. 
fungsi keluarga yang dia ambil yaitu fungsi Afektif dan fungsi perawatan dimana. Fungsi afektif yang dimiliki keluarga sebagai sumber kasih sayang dan reinforcementse hingga keluarga membentuk suatu iklim yang positif bagi anggota keluarga di dalamnya. Keberhasilan dari pelak-sanaan fungsi afektif keluarga akan membentuk konsep diri yang positif dari keluarga tersebut Maria, (2009). Pelaksanaan fungsi afektif keluarga berhubungan dengan pencapaian tujuan peran keluarga merawat anggota keluarga yang sakit.Keluarga mem-punyai peran utama dalam pemeliharaan kesehatan seluruh anggota keluarga dan bukan individu sendiri yang mengu-sahakan tercapainya tingkat kesehatan yang di inginkan.

Perawatan kesehatan keluarga berfungsi meningkatkan status kese-hatan anggota keluarga dengan cara mengenal masalah kesehatan keluarga, memutuskan tindakan kesehatan yang tepat bagi keluarga, merawat keluarga yang mengalami gangguan kesehatan, memodifikasi lingkungan keluarga untuk menjamin kesehatan, me-manfaatkan fasilitas pelayanan ke-sehatan, praktek diet keluarga, praktek tidur, praktek latihan dan rekreasi, praktek penggunaan obat terapeutik, alkohol, tembakau, serta praktek perawatan diri keluarga Suprajitno, (2004).

Berdasarkan observasi awal yang dilakukan pada bulan Oktober 2018 didapatkan informasi bahwa jumlah kunjungan pasien TB Paru tahun 2018 ke Puskesmas Tuminting Manado rata-rata 81 kunjungan baik pasien lama maupun pasien baru. Hasil wawancara dengan lima orang pasien TB Paru mereka cenderung putus minum obat karena alasannya jauh dari keluarga, dan tinggal hanya sendiri dan ada keluarga yang hanya mengabaikannya. Menurut perawat puskesmas yang bertanggung jawab pada kasus TB, sebagian klien yang terkena TB putus minum obat karena tidak ada keluarga yang mengantarnya untuk berobat, selain itu ada yang tinggal hanya sendiri tidak ada keluarga. Berdasarkan latar belakang di atas maka peneliti tertarik untuk mengetahui secara lebih mendalam Hubungan FungsiAfektif dan Perawatan Keluarga dengan kepatuhan pengobatan TB Paru di Puskesmas Tuminting Manado.

\section{METODE PENELITIAN}

Penelitian ini termasuk dalam jenis penelitian kuantitatif dengan menggunakan metode penelitian survei analitik untuk menganalisis hubunga kepercayaan dengan perilaku mencari pertolongan, Penelitian ini meng-gunakan desain penelitian cross sectional Setiadi, (2013).

Penelitian ini dilaksanakan di puskesmas tuminting manado pada bulan Mei 2019. Populasi penelitian ini seluruh penderita TB Paru di Puskesmas Tuminting Manado yang berjumlah 81 orang.Pengambilan sampel menggunakan teknik Accidental sampling, dengan rumus slovin maka didapatkan jumlah sampel 68 responden. Instrument penelitian yang digunakan untuk mengukur variabel fungsi afektif keluarga yaitu kuesioner yang pernah digunakan sebelumnya oleh Zulka (2015) dan fungsi perawatan keluarga di buat sendiri oleh peneliti, kuesioner fungsi afektif keluarga terdiri dari 22 pertanyaan dan fungsi perawatan keluarga terdiri dari 10 pernyaataan Masing-masing item pernyataan yang mendukung atau positif (favorable) negative (unfavorable) dengan pemberian bobot : kurang baik $\leq 55$, Baik > 55 , sedangkan fungsi perawatan kelurga Kurang Baik $\leq 25$, Baik $>25$ dan instrument penelitian yang digunakan untuk mengukur variabel kepatuhan pengobatan $\mathrm{Tb}$ paru yaitu kuesioner yang pernah di gunakan sebelumnya oleh Aris widianto (2016) yang telah di uji validitasnya. Di susun dalam 20 pernyataan Masing- masing jawaban memiliki 4 kategori yaitu $\mathrm{SS}=$ sangat setuju, $\mathrm{S}=$ setuju, $\mathrm{TS}=$ tidak setuju, $\mathrm{STS}=$ sangat tidak setuju. Skor penilain item yaitu 
$\mathrm{SS}=4, \mathrm{~S}=3, \mathrm{TS}=2, \mathrm{STS}=1$. Dengan bobot penilainan : tidak patuh $\leq 50$, patuh $<50$. Pengolahan data yang diperoleh dari hasil penelitian ini dianalisis menggunakan uji statistik melalui sistem komputer dengan beberapa tahap yaitu editing, coding, tabulasi data (Notoatmodjo, 2010). Analisa bivariat dalam penelitian ini yaitu untuk mengetahui hubungan fungsi afektif dan perawatan keluarga dengan kepatuhan pengobatan TB Paru di puskesmas tuminting manado. Peneliti meng-gunakan uji Uji Fisher Exact test dengan tingkat kepercayaan $95 \% \quad(\mathrm{p}=0,001)$ dan $(\mathrm{p}=0,003)$

\section{HASIL dan PEMBAHASAN}

\section{Karakteristik Responden}

Tabel 1. Distribusi Responden Berdasarkan Umur

\begin{tabular}{lll}
\hline Umur & n & \% \\
\hline 18-30 Thn & 16 & 23,5 \\
$31-40$ Thn & 18 & 26,5 \\
41-50 Thn & 11 & 16,2 \\
$>50$ Thn & 23 & 33,8 \\
\hline Total & $\mathbf{6 8}$ & $\mathbf{1 0 0}$
\end{tabular}

Sumber : Data Primer 2019

Tabel 1 di atas menjelaskan dari 68 responden, hasil menunjukan bahwa TB paru di puskesmas tuminting manado didapati sebagian besar responden berumur $>50$ thn 23 responden (33.8\%). Hasil penelitian ini sesuai dengan asra septia (2014) dimana 58 responden, 23 diantaranya didaptkan 45-59 tahun orang dewasa akhir Mayoritas responden pada penelitian ini berada pada kelompok dewasa awal dan akhir. Menurut Ani Rusnoto, (2008), penyakit TB Paru merupakan penyakit Kronis yang dapat menyerang semua lapisan usia, selain menyebabkan morbilitas dan mortalitas yang cukup tinggi juga dapat merugikan secara ekonomi karena hilangnya jam kerja.
Tabel 2. Karakteristik responden berdasarkan jenis kelamin

\begin{tabular}{|c|c|c|}
\hline Jenis Kelamin & $\mathbf{n}$ & $\%$ \\
\hline Perempuan & 30 & 44.1 \\
\hline Laki-laki & 38 & 55,9 \\
\hline Total & 68 & 100 \\
\hline
\end{tabular}

Tabel 2 di atas menjelaskan bahwa 68 responden didapat sebagian besar berjenis kelamin laki-laki sebanyak 38 responden $(55,9 \%)$ dan perempuan sebanyak 30 responden $(44,1 \%)$ Hasil penelitian ini sejalan dengan sitepu (2009) yang menunjukan bahwa jenis kelamin paling banyak terdapat pada jenis kelamin laki-laki sebanyak 72 orang laki-laki memiliki mobilitas yang lebih tinggi diban-dingkan perempuan sehingga kemung-kinan untuk terpapar kuman penyebab TB Paru lebih besar, selain itu kebiasaan laki-laki mengkomsumsi rokok, minuman alcohol dan keluar malam hari dapat menurunkan sistem kekebalan tubuh. Menurut penelitian yang telah dilaksanakan Maulidia (2014), penderita TB Paru cenderung lebih tinggi pada laki-laki dibandingkan perempuan. Pada karakteristik jenis kelamin ini laki-laki lebih tinggi karena merokok tembakau dan minum alcohol sehingga dapat menurunkan sistem pertahanan tubuh, sehingga lebih mudah terpapar dengan agen penyebab TB Paru.

Tabel 3. Karakteristik responden bersadarkan pendidikan

\begin{tabular}{lcc}
$\begin{array}{l}\text { Pendidikan } \\
\text { terakhir }\end{array}$ & n & \% \\
\hline SD & 12 & 17,6 \\
SMP & 26 & 38,2 \\
SMA & 26 & 38,2 \\
S1 & 4 & 5,9 \\
$\quad$ Total & $\mathbf{6 8}$ & $\mathbf{1 0 0 . 0}$ \\
\hline
\end{tabular}

Sumber :Data primer : 2019 
Hasil penelitian menunjukan dari 68 responden didapati SMP dan SMA sebanyak 26 responden $(38,2 \%)$. Menurut penelitian panjaitan (2012), pendidikan menjadi salah satu factor resiko penularan penyakit Tuberkulosis. Rendahnya tingkat pendidikan res-ponden, akan berpengaruh pada pemahaman tentang penyakit Tuberkulosis. Masyarakat yang merasakan pendidikan tinggi, tujuh kali lebih waspada ter-hadap TB Paru ( gejala, cara penularan, pengobatan) bila dibandingkan dengan masyarakat yang hanya menempu pendidikan dasar atau lebih rendah. Pendidikan yang rendah dihubungkan dengan rendahnya tingkat kewaspadaan terhadap penularan TB Paru.

Tabel 4. Karakteristik responden bersadarkan pekerjaan

\begin{tabular}{lcc}
\hline Pekerjaan & n & \% \\
\hline Petani & 21 & 30.1 \\
Pedagang & 2 & 2,9 \\
IRT & 15 & 22.1 \\
PNS & 1 & 1,5 \\
Sopir & 4 & 5,9 \\
Tidak bekerja & 11 & 16.2 \\
Wiraswasta & 12 & 17,6 \\
Wirausaha & 2 & 2,9 \\
\hline Total & $\mathbf{6 8}$ & $\mathbf{1 0 0}$
\end{tabular}

Sumber :Data primer : 2019

Tabel 4 di atas menjelaskan bahwa Sebagian besar responden adalah petani sebanyak 20 responden $(29,4 \%)$ Di sampaikan amira (2008) bahwa umumnya individu yang mempunyai penghasilan kurang menyebabkan kemampuan memperoleh status gizi menjadi kurang baik dan kurang seimbang sehingga berdampak pada menurunnya status kesehatan. Menurut Illu Picauly dan Ramang (2012), semakin memburuknya keadaan ekonomi seseorang, kelompok pen-duduk miskin bertaambah banyak, daya beli makin menurun, kemampuan memenuhi kebutuhan pokok makin berkurang dan dikwatirkan keadaan ini akan memperburuk kondisi kesehatan masyarakat khususnya penderita TB Paru.

\section{Analisa Univairat}

Tabel 5. Variabel Fungsi Afektif dan Perawatan Keluarga dengan Kepatuhan Pengobatan

\begin{tabular}{|c|c|c|c|}
\hline Variabel & Kategori & $\mathbf{n}$ & $\%$ \\
\hline Fungsi & Baik & 62 & 91.2 \\
\hline $\begin{array}{l}\text { Afektif } \\
\text { Keluarga }\end{array}$ & $\begin{array}{l}\text { Kurang } \\
\text { baik }\end{array}$ & 6 & 8.8 \\
\hline Total & & 68 & 100 \\
\hline $\begin{array}{l}\text { Fungsi } \\
\text { Perawatan } \\
\text { Keluarga }\end{array}$ & $\begin{array}{l}\text { Baik } \\
\text { Kurang } \\
\text { baik }\end{array}$ & $\begin{array}{l}64 \\
4\end{array}$ & $\begin{array}{c}94,1 \\
5,9\end{array}$ \\
\hline Total & \multicolumn{2}{|c|}{68} & 100 \\
\hline $\begin{array}{l}\text { Kepatuhan } \\
\text { pengobatan }\end{array}$ & $\begin{array}{l}\text { Patuh } \\
\text { Tidak } \\
\text { patuh }\end{array}$ & $\begin{array}{c}61 \\
7\end{array}$ & $\begin{array}{l}89,7 \\
10,3\end{array}$ \\
\hline Total & & & 100 \\
\hline
\end{tabular}

Fungsi afektif keluarga didapati sebagian besar responden dengan keadaan baik berjumlah 62 responden $(91,2 \%)$ dan kurang baik 6 responden $(8,8 \%)$. Sedangkan fungsi perawatan keluarga dengan keadaan baik berjumlah 64 responden $(94,1 \%)$ dan kurang baik berjumlah 4 responden $(5,9 \%)$. dan kepatuhan pengobatan TB Paru yang patu berobat sebagian besar berjumlah 61 responden $(89,7 \%)$ dan tidak patuh berobat 7 responden (10,3\%). Fungsi Afektif keluarga yang utama mengajarkan segala sesuatu untuk mempersiapkan anggota keluarga berhubungan dengan orang lain, fungsi sosialisasi adalah fungsi mengem-bangkan dan tempat melatih anak berkehidupan social sebelum menin-ggalkan rumah untuk berhubungan dengan orang lain di luar rumah, dan fungsi perawatan atau pemeliharaan kesehatan, yaitu fungsi untuk 
mempertahankan keadaan kesehatan anggota keluarga tetap memiliki produktivitas tinggi. Friedman (2010) menyatakan bahwa keluarga memiliki peran untuk melaksanakan praktek asuhan kesehatan, yaitu untuk mencegah terjadinya gangguan kesehatan atau merawat anggota keluarga yang sakit dengan cara meningkatkan kesanggupan ke-luarga yang sakit agar dapat melakukan fungsi dan tugas perawatan kesehatan dirinya. Keluarga sangat penting dalam merawat anggota keluarga yang sedang sakit penelitian Residan dan lystiana, berperan sebagai pendukung dan ber-peran sebagai pengambil keputusan dalam merawat anggota keluarganya paska strok saat dirumah.Waktu peng-obatan yang lama menyebabkan penderita sering terancam putus berobat selama masa penyem-buhan berbagai alasan, antara lain merasa sudah sehat atau faktor ekonomi akibat adalah pola pengobatan harus dimulai dari awal dengan biaya yang bahkan menjadi lebih besar serta menghabiskan waktu berobat yang lama Riskesdas (2010).

Safi (2018). pengobatan TB Paru membutuhkan waktu panjang (sampai 6 atau 8 bulan) untuk mencapai penyem-buhan dan panduan (kom-binasi) beberapa macam obat, sehingga tidak jarang pasien berhenti minum obat sebelum masa pengobatan selesai yang beraakibat pada kegagalan dalam peng-obatan TB.

\section{Analisa Bivariat}

Tabel 6. Hubungan fungsi afektif

keluarga dengan kepatuhan pengobatan $\mathrm{Tb}$ paru

\begin{tabular}{|c|c|c|c|c|c|c|c|}
\hline \multirow{3}{*}{$\begin{array}{l}\text { Fungsi } \\
\text { Afekti } \\
\text { Keluarg } \\
\text { a }\end{array}$} & \multicolumn{4}{|c|}{$\begin{array}{l}\text { Kepatuhan } \\
\text { Pengobatan }\end{array}$} & & & \\
\hline & \multicolumn{2}{|c|}{ Patuh } & \multicolumn{2}{|c|}{$\begin{array}{l}\text { Tidak } \\
\text { patuh }\end{array}$} & \multicolumn{2}{|c|}{ Total } & \multirow[t]{2}{*}{$\begin{array}{l}\mathbf{P} \\
\text { value }\end{array}$} \\
\hline & $\mathrm{n}$ & $\%$ & $\mathrm{n}$ & $\%$ & $\mathrm{n}$ & $\%$ & \\
\hline Baik & 59 & 95,2 & 3 & 4,8 & 62 & 100,0 & 0,001 \\
\hline $\begin{array}{l}\text { Kurang } \\
\text { baik }\end{array}$ & 2 & 33,3 & 4 & 66,7 & 6 & 100,0 & \\
\hline Total & 61 & $\mathbf{8 9 , 7}$ & 7 & 10,3 & 68 & 100,0 & \\
\hline
\end{tabular}

Sumber : data primer 2019
Hasil penelitian menunjukan dari 68 responden 62 responden mengalami keadaan baik, 59 responden diantaranya patuh dalam pengobatan TB Paru dan 3 responden tidak patuh menjalankan pengobatan. Untuk Fungsi Afektif Kurang Baik ada 6 responden, 2 responden patuh menjalankan peng-obatan dan 4 responden tidak patuh menjalankan pengobatan.odds ratio 39.3 dan Hasil Uji Hipotesis dengan Uji Cji-squer $\left(\mathrm{x}^{2}\right)$ yang dilanjutkan dengan uji Fisher Exact dengan tingkat kepercayaan $95 \% \quad(<0,05)$, menunjukan adanya Hubungan Fungsi Afektif Keluarga Dengan Kepatuhan Peng-obatan TB Paru di Puskesmas Tuminting Manado ( $\mathrm{p}=0,001)$. Dari hasil penelitian Herryanto (2008), mengemukakan karakteristik kasus kematian penderita TB yang hampir tersebar pada semua kelompok umur, dan paling banyak pada kelompok usia 20-50 tahun yang merupakan usia produktif.

Riskesdes (2010), di ketahui bahwa privalensi TB Paru cenderung meningkat sesuai dengan bertambahnya usia lebih dari 65 tahun. Hal ini sejalan dengan pernyataan Subakti (2014) bahwa semakin Tua Umur seseorang maka semakin banyak fungsi organ tubuh yang mengalami gangguan atau masalah yang berdampak pada kebutuhan akan pemeliharaan ke-sehatan, usia dewasa dan diikuti oleh usia Tua merupakan kelompok yang paling sering terkena TB di Amerika Serikat pada tahun 2008. Komponen dari fungsi afektif keluarga yang harus dipenuhi keluarga adalah Friedman, (2010) memelihara saling asuh, perkembangan hubungan yang akrab, keseimbangan saling menghormati, pertalian dan identifikasi, menghasilkan kenyamanan antar anggota keluarga , keterpisahan keter-paduan, pola kebutuhan dan respon, peran terapeutik . 
Tabel 7. Hubungan fungsi perawatan keluarga dengan kepatuhan pengobatan TB paru

\begin{tabular}{|c|c|c|c|c|c|c|c|}
\hline \multirow{3}{*}{$\begin{array}{l}\text { Fungsi } \\
\text { pe- } \\
\text { rawata } \\
\text { n }\end{array}$} & \multicolumn{7}{|c|}{$\begin{array}{l}\text { Kepatuhan } \\
\text { Pengobatan }\end{array}$} \\
\hline & \multicolumn{2}{|c|}{ Patuh } & \multicolumn{2}{|c|}{$\begin{array}{l}\text { Tidak } \\
\text { patuh }\end{array}$} & \multicolumn{2}{|c|}{ Total } & $\begin{array}{l}\mathrm{P} \\
\text { valve }\end{array}$ \\
\hline & $\mathrm{n}$ & $\%$ & $\mathrm{n}$ & $\%$ & $\mathrm{n}$ & $\%$ & \\
\hline Baik & 60 & 93,8 & 4 & 6,3 & 64 & 100,0 & 0,003 \\
\hline $\begin{array}{c}\text { Kurang } \\
\text { baik }\end{array}$ & 1 & 25,0 & 3 & 75,0 & 4 & 100,0 & \\
\hline Total & 61 & 89,7 & 7 & 10,3 & 68 & 100,0 & \\
\hline
\end{tabular}

Sumber: data primer 2019

Hasil penelitian menunjukan dari 68 responden 64 responden mengalami keadaan baik, 60 responden diantaranya Patuh dalam pengobatan dan 4 responden tidak patuh dalam peng-obatan. Untuk Fungsi Perawatan Kurang Baik ada 4 responden, 1 responden patuh menjalankan pengobatan dan 3 responden tindak menjalankan pengobatan.odds ratio 45.0 dan Hasil uji Hipotesis dengan menggunakan Uji-Chisquer $\left(\mathrm{x}^{2}\right)$ yang dilanjutkan dengan Uji Fisher Exact dengan tingkat kepercayaan $95 \% \quad(<0,05)$ menunjukan adanya Hubungan Fungsi Perawatan Keluarga Dengan Kepatuhan Peng-obatan TB Paru di Puskesmas Tuminting Manado ( $\mathrm{p}=0,003)$.

Berdasarkan hasil penelitian ini sejalan dengan Boidowi di semarang bahwa pendidikan berpengaruh terhadap kepatuhan berobat pasien TB Paru, tingkat pen-didikan formal merupakan landasan seseorang dalam memahami sesuatu. Pendidikan yang rendah mengakibatkan responden kurang informasi berkaitan dengan penularan dan pengobatan TBC. Menurut Notoadmojo (2010), bahwa semakin tinggi pendidikan individu semakin mudah penerimaan informasi, tetapi semakin rendah pendidikan semakin sulit untuk menerima informasi jadi pendidikan mempengaruhi diri individu. temuan penelitian ini sesuai dengan hasil Riskesdas (2007), yang menemukan prevalensi TB Paru empat kali lebih tinggi pada pendidikan rendah dibandingkan pendidikan tinggi Depkes RI, 2008).

Novitasari, (2014). dan terdapat beberapa tugas dalam melaksanakan perawatan kesehatan keluarga menurut setiadi (2013) yaitu: Mengenal masalah kesehatan, Mengambil keputusan mengenai tin-dakan kesehatan yang tepat, Merawat anggota keluarga yang mengalami ma-salah kesehatan, Modifikasi lingkungan fisik dan psikologis, Menggunakan fasi-litas kesehatan yang ada disekitar keluarga.

Kriteria Kurang Baik tetapi patuh menjalankan pengobatan, dari wa-wancara yang peneliti lakukan mereka semangat berobat karena masih ingin berkumpul dengan keluarganya. Adapun konsep diri responden yang baik yang mendominasi ini karena mereka menerima penyakit tuberkulosis yang diderita dengan selalu menjalani peng-obatan untuk mencapai kesembuhan, menerima penurunan berat badan saat ini, dan responden percaya diri walaupun harus menjaga jarak saat berkontak langsung dengan keluarga maupun orang lain. Hal ini menurut Manalu (2010) mengatakan bahwa konsep diri adalah semua ide, pikiran, kepercayaan dan pendirian yang diketahui individu tentang dirinya dan mempengaruhi individu dalam ber-hubungan dengan orang lain.

Maulidia, (2014) menyatakan bahwa penderita tuberkulosis sangatlah membutuhkan peran keluarga dalam kesembuhan yang berupa memberikan sarana perasanan, menyediakan dana pengobatan, meluangkan waktu untuk mendampingi berobat dan saat dirumah maupun bergaul dilingkungan seki-tarnya. Menurut Manalu (2010), faktor yang mempengaruhi dukungan keluarga diantaranya menerapkan fungsi keluarga yaitu sejauh mana keluarga mempengaruhi anggota ke-luarga lain saat mengalami masalah kesehatan serta membantu dalam memenuhi kebutuhan.

Penelitian yang dilakukan sebe-lumnya oleh Asra Septiani (2014) bahwa terdapat 
Hubungan Dukungan Keluarga dengan Kepatuhan Minum Obat pada Penderita TB Paru di Rumah Sakit Umum Daerah Arifin Achmad. Dengan skor sebagai berikut didapatkan 43 orang mendapati dukungan keluarga positif dan 15 orang mendapatkan dukurngan keluarga ne-gatif. Dukungan keluarga merupakan faktor paling penting keberhasilan pasien TB Paru dalam mematuhi program pengobatan.Keluarga me-rupakan unit terkecil dari masyarakat yang besar pengaruhnya dalam ke-hidupan seseorang terlebih lagi dalam kesehatan.keluarga dapat berperan aktif dalam melindungi anggota keluarga yang sakit, kemapuan keluarga dalam memberikan perawatan kesehatan mempengaruhi status kesehatan ke-luarga. Selain itu pengetahuan keluarga sehat dan sakit juga mempengaruhi prilaku keluarga dalam menyelesaikan masalah kesehatan keluarga, Friedman (2010).

Penelitian ini didukung oleh peneliti Subakti (2014) tentang Hubungan Dukungan Keluarga dengan Tindakan Penderita TB Paru Me-laksankan kontrol ulang di Puskesmas Sidomulyo bahwa berdasarkan du-kungan keluarga yang positif yaitu sebanyak 23 responden $(56,11 \%)$ dan 31 responden $(75,6 \%)$ diantaranya memiliki tindakan untuk melakukan kontrol ulang secara rutin di Puskesmas. Penelitian lain yang mendukung adalah yang dilaksankan oleh Pare, Amiruddin dan Leida (2012), yang menemukan bahwa ada Hubungan Dukungan Keluarga dengan Kepatuhan minum obat penderita TB paru. Dukungan keluarga merupakan salah satu faktor yang mempengaruhi kepatuhan untuk pengobatan TB paru, dimana keluarga inti maupun keluarga besar berfungsi sebagai sistem pendukung bagi anggota keluarganya.Fungsi dasar keluarga itu yaitu fungsi perawatan kesehatan.Fungsi perawatan kesehatan adalah kemampuan keluarga untuk merawat anggota keluarga yang mengalami masalah kesehatan.
Keluarga perlu meberikan dukungan yang positif untuk melibatkan keluarga sebagai pendukung pengobatan sehingga adanya kerjasama dalam pemantauan pengobatan antara petugas dan anggota keluarga yang sakit.(Friedman, Bowden \&Jones,2010)

\section{SIMPULAN}

Hasil dari pembahasan Hubungan Fungsi Afektif dan Perawatan Keluarga dengan Kepatuhan Pengobatan TB Paru di Puskesmas Tuminting Manado bahwa :Sebagian besar gambaran fungsi Afektif Ke-luarga TB Paru di Puskesmas Tuminting Manado adalah Baik. dan Se- bagian besar gambaran fungsi pe- rawatan keluarga TB Paru di puskesmas Tuminting Manado adalah Baik. Se-bagian besar gambaran pengobatan $\mathrm{Tb}$ Paru di puskesmas Tuminting Patuh dalam Pengobatan.Juga Terdapat Hu-bungan antara Fungsi Afektif Keluarga Dengan Kepatuhan Pengobatan TB Paru di Puskesmas Tuminting Manado.Terdapat Hubungan antara Fungsi Perawatan Keluarga Dengan Kepatuhan Pengobatan TB Paru di Puskesmas Tuminting Manado.

\section{DAFTAR PUSTAKA}

Aris Widiyanto (2016) Hubungan kepatuhan minum obat denga kesembuhan pasien tuberculosis paru BTA Positif di puskesma delanggu kabupaten klaten

Asra Septia, hubungan dukungan keluarga dengan kepatuhan minum obat pada penderitaTBparu.https://media.neliti. com/media/publications/185830-IDhubungan-dukungan-keluargadengan-kepatu.pdf (diaskes 26 september 2018)

Departemen Kesehatan RI., 2009, Pedoman Nasional Penanggulangan Tuberkulosis Paru, Jakarta, Depkes RI

Depker RI. (2010). Riset kesehatan dasar. 
Jakarta: Badan Litbangkes Depkes RI.

Friedman, M. 2010. Buku ajaranan keperawatan keluarga, riset, teori, dan praktek. Edisi ke-5 I. Jakarta EGC

Freidman, M. M., Bowden, V. R., \& Jones, E.G. (2010). Buku ajar keperawatan

keluarga: Riset, teori, dan praktik, alih bahasa, Akhir Yani S. Hamid dkk; Edisi 5. Jakarta: EGC.

Maulidia, D.F. (2014). Hubungan antara dukungan keluarga dan kepatuhan minum obat pada penderita tuberculosis di wilayah ciputat tahun2014 (diaskes 18 mei 2019)

Maria H. Bakri, SKM., M. Kes asuhan keperawatan keluarga

Manalu H.S.P.(2010). Faktor-faktor yang mempengaruhi kejadian TB paru dan upaya penanggulangannya.indonesia jurnal of health ecology, 2010,9,4

Maulidia, D.F. (2014). Hubungan antara dukungan keluarga dan kepatuhan minum obat pada penderita tuberculosis di wilayah ciputat tahun2014 (diaskes 18 mei 2019)

Novitasari, I.A. (2014). Hubungan antara dukungan keluarga terhadap konsep diri pada penderita TBC dalam proses pengobatan di wilayah kerja puskesmas bendosari sukoharjo (Doctoral dissertation, universitas muhammadiyah Surakarta).(diaskes 18 mei 2019)

Notoadmodjo, S. (2010). Metodologi Penelitian Kesehatan, Jakarta:Rineka Cipta

Rukmini,R, \& Chatarina, U.W.(2011). Faktor-faktor yang berpengaruh terhadap kejadian Tb Paru dewasa di Indonesia (analisis data riset kesehatan dasar tahun 2010) bulletin penelitian sistem kesehatan,14(4)

Rusnoto, R. (2008). Faktor-faktor yang berhubungan dengan kejadian tb paru pada usia dewasa (Studi kasus di balai pencegahan dan pengobatan penyakit paru Pati). Jurnal Epidemiologi.

Hiswani. (2009), Tuberkulosis merupakan penyakit infeksi yang masih menjadi masalah kesehatan masyarakat.Diakesdarihttp://library .usu. ac.id/download/fkmhiswani6. pdf pada tanggal 10 April 2014.

Illu, S. I. D.. Picauly, I., \& Ramang, R.

(2012). Faktor-faktor penentu kejadiantuberkulosis paru pada penderita anak yang pernah berobat di RSUD W.Z Yohanes Kupang. Diakses melalui

http://www.academia.edu/4915863/

faktorfaktor_penentu_kejadian_tuberk ulosisparu_pada_penderita_anak_yang _pernah_berobat.pdf pada tanggal 23 Mei2014

Pare, L. Amiruddin R, \& Leida I. (2012). Hubungan antara pekerjaan. PMO pelayanan

Safii, S., Putri, S. T., \& Suparto, T. A. (2018). Gambaran Kepatuhan Pasien Tuberkulosis Paru Terhadap Regimen Terapeutik Di Puskesmas Padasuka. JURNAL PENDIDIKAN KEPERAWATAN INDONESIA, 1(2), 98-104

Setiadi, (2013), Konsep dan Praktek Penulisan Riset Keperawatam, Edisi 2, Yogyakarta; Graha Ilmu

Suprajitno, S.kep Asuhan keperawatan keluarga (diaskes 21 mei 2019)

Subhakti, K.A. (2014). Hubungan dukungan keluarga dengan tindakan penderita tb paru melakukan control 
e-journal Keperawatan(e-Kp) Volume 7 Nomor 2, Agustus 2019

ulang dipuskesmas sidomulyo. Jurnal online mahasiswa (JOM) bidang ilmu keperawatan, 1 (1),1-6. (diaskes 18 mei 2019)

WHO. (2009). Defenition and diagnosis of pulmonolgy tuberculosis. Diakses darihttps://mdgsgoals.com.who.int/ sree/ pada tanggal 27 Desember 2007.

WHO. (2013). Report tuberculosis in thworld. Diakses dari https:// extranet.who.int/sree /Reports padatanggal 27 Desember 2007

Zulka, A. N. (2015). Hubungan Pelaksanaan Fungsi Afektif Keluarga dengan Tingkat Harga Diri Klien Kusta di Wilayah Kerja Puskesmas Tanggul dan Sumberbaru Kabupaten Jember 